\title{
Vertical Expansion: A Solution for Future Container Terminals
}

\author{
Nima Zaerpour ${ }^{1, *}$, Amir Gharehgozli ${ }^{2}$, René de Koster $^{3}$ \\ ${ }^{1}$ College of Business Administration, California State University San Marcos, San Marcos, CA, USA \\ ${ }^{2}$ College of Business and Economics, California State University Northridge, Northridge, CA, USA \\ ${ }^{3}$ Rotterdam School of Management, Erasmus University, 3000 DR Rotterdam, Netherlands \\ nzaerpour@csusm.edu,amir.gharehgozli@.csun.edu,rkoster@rsm.nl
}

\begin{abstract}
Container terminals play a major role in the growth of international trade. They need to accommodate the increasing number of containers while their space is limited, particularly close to major cities. One approach, often used in practice, is horizontal expansion through expensive land reclamation projects. In contrast, vertical expansion uses the available land more efficiently by storing containers in high-bay warehouses. In this paper, we study a next generation container terminal consisting of container storage towers. A container tower is a cylindrical structure which consists of multiple levels of storage locations, lifts, and input and output (I/O) points (or depots). The lifts can rotate and can move containers horizontally and vertically to transport containers between the storage locations and the $\mathrm{I} / \mathrm{O}$ points. We investigate several design questions: 1) What is the optimal configuration of a container tower? 2) How does a container tower compare to a traditional container block of the same storage capacity, in terms of throughput capacity? 3) Is a container tower financially feasible compared to an existing container block of the same storage capacity? 4) What are the impacts of varying design parameters on the container tower performance and its financial feasibility? Question 1 is answered by obtaining closed-form expressions for the tower travel time, formulating the problem as a nonlinear optimization model, and deriving closed-form expressions for the tower optimal configuration. Questions 2 and 3 are answered by using closed-form expressions in order to compare the performance of two systems. Question 4 is answered by a sensitivity analysis for the design parameters of the container tower. The results show that, compared to a traditional container block, the container tower can increase the annual throughput, while saving on the required footprint at competitive investment costs. In particular, the container tower can increase the annual throughput up to $120 \%$ compared to a container block of the same storage capacity.
\end{abstract}

Keywords: terminal layout; container tower; throughput; investment and operational costs

\footnotetext{
* Corresponding author: College of Business Administration, California State University San Marcos, San Marcos, CA, USA. Email: nzaerpour@,csusm.edu, TEL: +1 7607504272
} 


\section{Introduction}

Sea container terminals play a vital role in global supply chains. Due to a rapid growth in world trade and a huge increase in containerized goods, the turnover of container terminals has increased considerably (Zhen et al., 2016; Liu et al., 2016). Also, containerships have grown in size and it is expected that the growth will continue (Christiansen et al., 2013; Meng et al., 2014; Demir et al., 2016; Lee and Song, 2017; Fransoo and Lee, 2013). Back in the '60s and '70s it took almost 30 years to double the size of the ships. However, since 2000 the size of the containerships has doubled (from 8000 twenty-foot equivalent units (TEUs) in 2000 to 21,000 TEUs in 2016). Although these huge containerships bring benefits such as economies of scale, also deeper channels and bigger cranes are needed in the container ports. Furthermore, the land available to accommodate the increasing number of incoming containers delivered by such mega vessels is becoming scarce. Lack of space has driven the container terminal operators to stack containers multi-high in dense blocks of containers, using handling equipment like straddle carriers, rubber-tired gantry (RTG) cranes or rail-mounted gantry (RMG) cranes (Carlo et al, 2014a; Gharehgozli et al 2017a, 2015, and 2014b). Stacking containers multi-high often leads to reshuffling. A reshuffle is the removal of a container stacked on top of a desired container. This is a time-consuming task, and therefore expensive (Gharehgozli et al, 2017b and 2014a; Lin et al., 2015).

Until now, port authorities have expanded ports horizontally, often through land reclamation. The Port of Rotterdam's new Maasvlakte 2 ("www.maasvlakte2.com"), the Khalifa Port ("www.kizad.com") in Abu Dhabi or Hong Kong's container port ("www.hkctoa.com"), are examples of this. However, land reclamation from sea or ocean, is extremely expensive. For example, Port of Rotterdam has invested around $€ 3$ billion in the Maasvlakte 2 project to extend the port by approximately 1000 hectares (Gharehgozli et

al., 2017c). This is approximately three times more than the Maasvlakte 1 project with a total cost of $€ 1.2$ billion. In another instance, China has spent \$18 billion to build the new Yangshan deep-water port ("www.yangshanterminal.com") on an island near Shanghai, which required the construction of the 31.3 km Donghai Bridge (Marine Insight, 2013). Finally, the dry port or extended gate idea is another attempt to increase the capacity of ports by horizontal expansion. Simply put, the idea is to use hinterland terminals as gates for deep-sea terminals in the port area (Crainic et al., 2015; Zuidwijk et al., 2012; Zuidwijk and Veenstra, 2012). In addition to being expensive, the horizontal expansion of container ports results in new 
operational challenges. It may slow down the serving time of the vessels as the containers need to travel longer to their assigned storage locations.

Vertical expansion, i.e. using the available land more efficiently by storing container in a high-bay container warehouse could be an alternative (Kho, 2013; Matinlauri, 2015; Ez-lndus, 2016; VMW systems, 2016; SingaPORT, 2013). Vertical expansion can avoid the huge investment in land reclamation or acquisition and may better serve future mega vessels.

In this paper, we study a next generation container tower system which allows for high storage density while stored containers are individually accessible without reshuffling. The footprint of such systems is much smaller than for a traditional container block. The saving obtained from the smaller footprint might offset the higher cost of technology. Figure 1 gives an impression of these container towers.

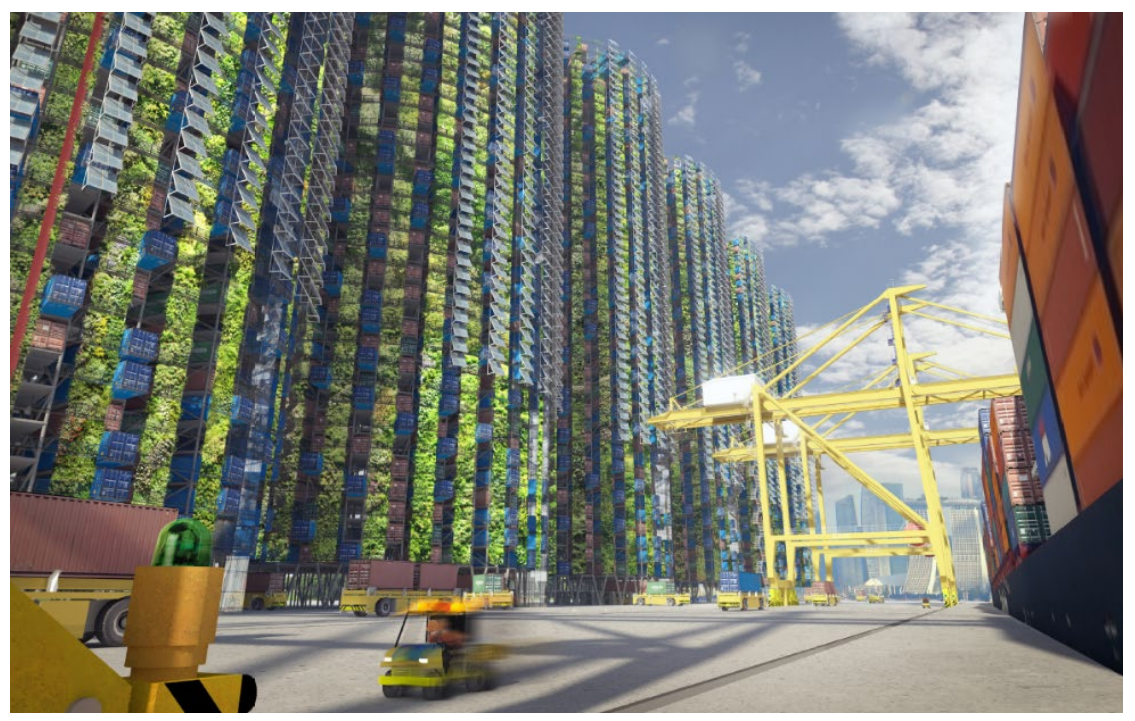

Figure 1. A next generation high-density container tower port (image courtesy of Casanova \& Hernandez Architects, http://www.casanova-hernandez.com/ch_projects/u_urbanism/chronology/u024)

The cylindrical structure of a container tower is more preferable than a rectangular cuboid layout. First, a round structure is stronger making it possible to reach higher heights. Second, at greater heights, a structure is vulnerable to strong winds. However, the round shape has a smaller surface that gets hit by the wind as it flows around the structure. Third, compared to a rectangular layout, no reshuffling is needed as each container is placed on an individual chassis within the tower. In addition, the circular design of a container tower (compared to rectangular next generation terminal designs) allows a large number of Input/Output (I/O) points. The AGVs can enter the tower from each angle at the bottom of the tower (see Figure 2a). This reduces the waiting times for the AGVs entering the container tower. In addition, due to the extra capacity that container towers provide, containers of each ship can be stacked in one or more dedicated 
towers close to the ship. Therefore, ground transport equipment will have shorter travel distances from container towers to ships. This helps to efficiently manage the traffic flow in the terminal.

The main components of the container tower are multiple levels of storage locations, lifts, and Input and output (I/O) points (or depots) (see Figure 2a):

- Storage locations store containers. All storage locations have standard size accommodating up to $40 \mathrm{ft}$ containers.

- I/O points connect the container tower to the rest of the terminal. The lifts retrieve containers to the I/O points to be transported out of the container tower.

- Lifts move the containers vertically inside the container tower. To avoid collision of lifts, they cannot pass each other. For instance, in a tower with three lifts, each lift only rotates a maximum of 120 degrees serving a third of the tower (see Figure $2 b$ ).

- Shuttles or telescopic extensions of the lifts move containers in horizontal direction to or from their storage locations.

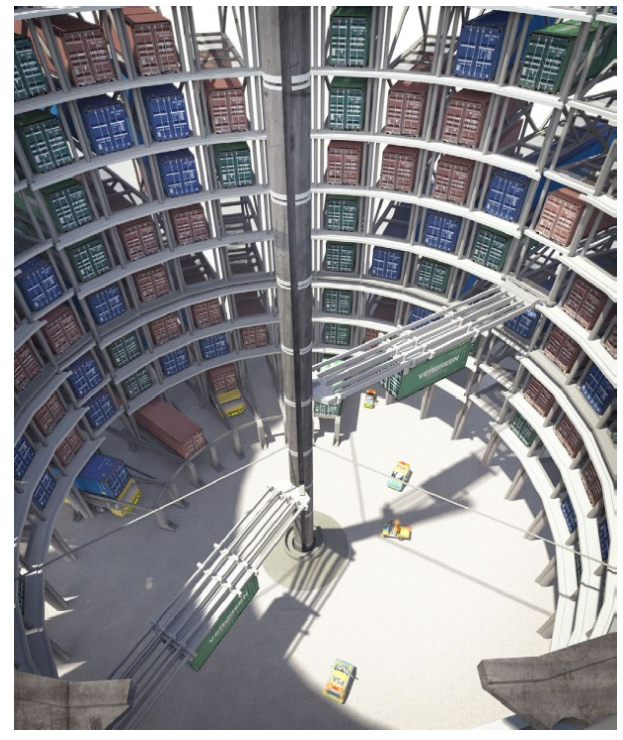

(a) An inside view of a container tower

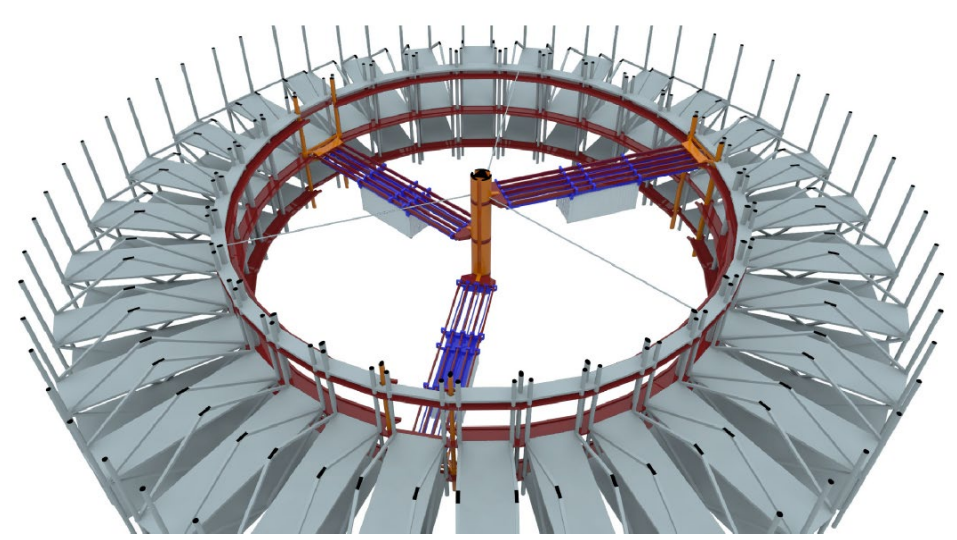

(b) Three lifts each rotating 120 degrees

Figure 2. An overview of the lifts in a container tower (images courtesy of Casanova \& Hernandez Architects) An incoming container is transferred from the containership to an automated guided vehicle (AGV) using a quay crane (see Figure 1). In order to store the container, the AGV transports the container to one of the $\mathrm{I} / \mathrm{O}$ points (see Figure 2a). The lift serving that I/O point is capable of moving in a three dimensional space. It picks up the container, moves toward the desired storage location in vertical direction to reach the desired level. Then, the lift rotates to the front face of the desired storage location. Finally, the container moves in 
horizontal direction to the desired location using a shuttle or telescopic extension of the lift (in section 4, we also consider a design where the vertical and rotational movements of each lift can happen simultaneously). Figure 3 shows the three movement types.
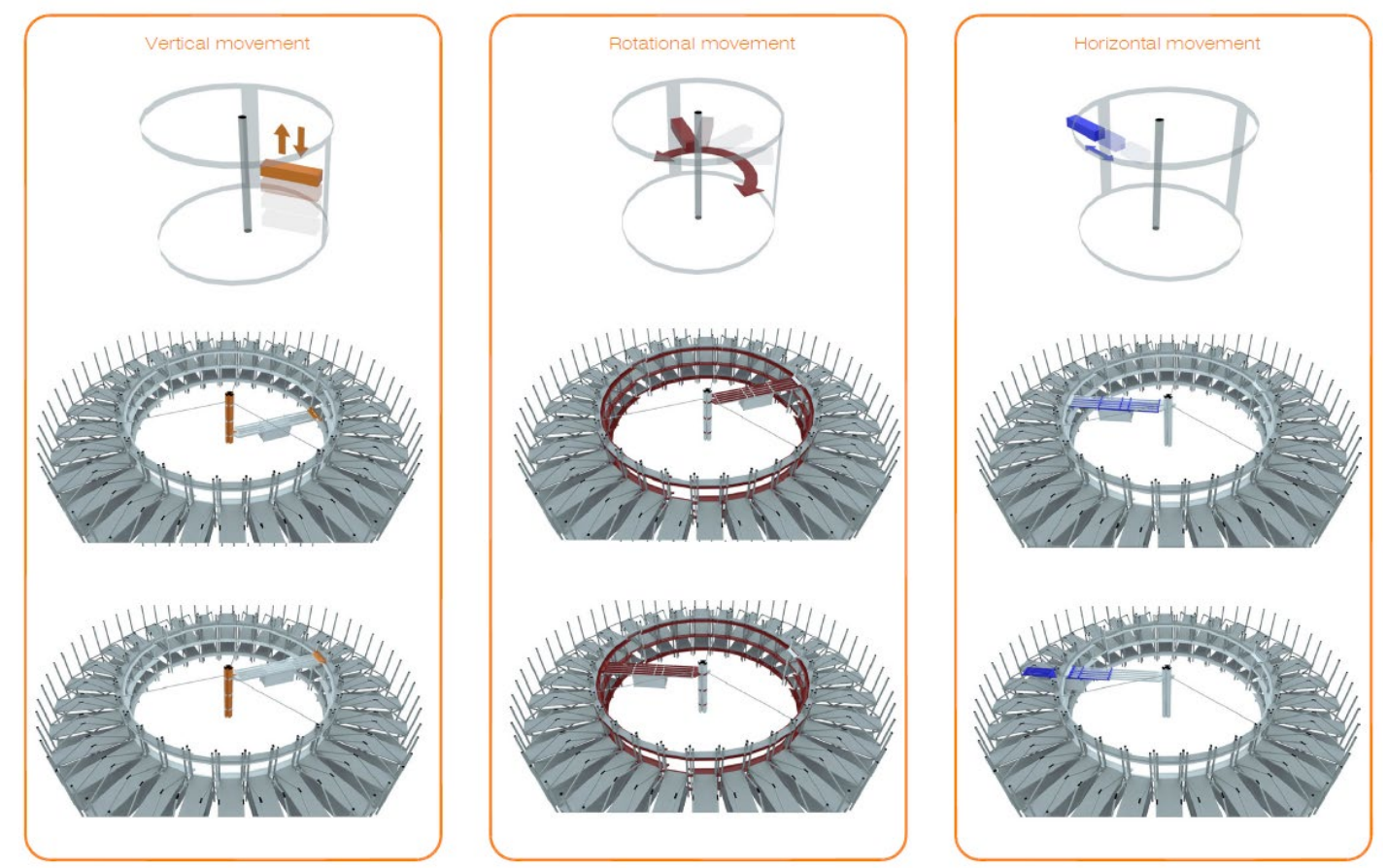

Figure 3. Three movement types of a lift in a container tower (image courtesy of Casanova \& Hernandez Architects)

Currently, such systems are used for automated car parking (see the literature review section). However, many research questions still have to be answered, including cycle time calculations for a given size and, in particular, cost comparisons have to be made. We answer the following questions in this paper:

1. What is the expected response time of an arbitrary retrieval request for a given container tower configuration? What is the optimal tower configuration that minimizes the expected response time?

2. How does a container tower compare to a traditional block of the same storage capacity in throughput and financial performance? What is the optimal tower configuration that minimizes the investment cost for a given expected response time?

In section 2, we first, review some recent innovative container terminal designs. Then, in section 3 , we focus on the proposed container tower and evaluate the system performance in terms of annual throughput. In addition, we obtain closed-form expressions for the optimal tower configuration (radius, height) which minimizes the expected retrieval time of an arbitrary request. In section 4, we study the investment and operational costs of the container tower and make a comparison with a container block by obtaining closed- 
form expressions. In addition, we derive closed-form formulas for the optimal tower configuration which minimizes the tower investment. In section 5, we present the numerical results for a realistic range of design parameters. Section 6 concludes the paper.

\section{Literature review on container terminal design}

Logistics planning and control at seaport container terminals are among the most popular transportation research areas, according to the recent study by Sun and Yin (2017) on 17,163 articles published in 22 leading transportation journals between 1990 and 2015. Multiple reviews on container terminal operations have been published in the last decade (see, e.g. Vis and de Koster, 2003; Steenken et al., 2004; Günther and Kim, 2005; Murty et al., 2005; Stahlbock and Voß, 2008; Gorman et al., 2014; Carlo et al., 2013, 2014a, 2014b; Gharehgozli et al., 2016). In addition, several authors have studied the effect on the performance in automated container terminals of layout variables such as the size of the blocks, the number of blocks, and the type of material handling equipment (e.g. Kim et al. (2008), Wiese et al. (2011), Petering and Murty (2009), Lee and Kim (2010), Petering (2011), Kemme (2012), Lee and Kim (2013), and Roy et al. (2014)). However, little has been published on new container terminal designs, although the need for such research has been recognized in the literature (Fransoo and Lee, 2013).

Current container terminal designs can be divided into two general categories: (1) the design for export and import terminals, common in Europe, East Asia, and America, and (2) the design transshipment terminals, common in Southeast Asia and the Middle-East. Particularly in export and import terminals the blocks are often perpendicular to the quay decoupling the seaside and landside operations (for example, the HHLA Terminal Altenwerder in Port of Hamburg). In transshipment terminals, blocks are usually parallel to the quay facilitating transshipment of container from ship to ship (for example, the Tanjong Pagar Container Terminal in Port of Singapore).

Some recent studies reveal that designs in which blocks and travel paths are diagonal to the quay, or in which blocks are divided into smaller blocks with I/O points in the middle (Figure 4), can result in more flexibility and higher efficiency (Gue, 2014; Ivanović, 2014). In warehouses, such new layouts have achieved a reduction in travel time of up to 20\% (Öztürkoǵlu et al., 2012; Gue and Meller, 2009; Gue et al., 2012). 


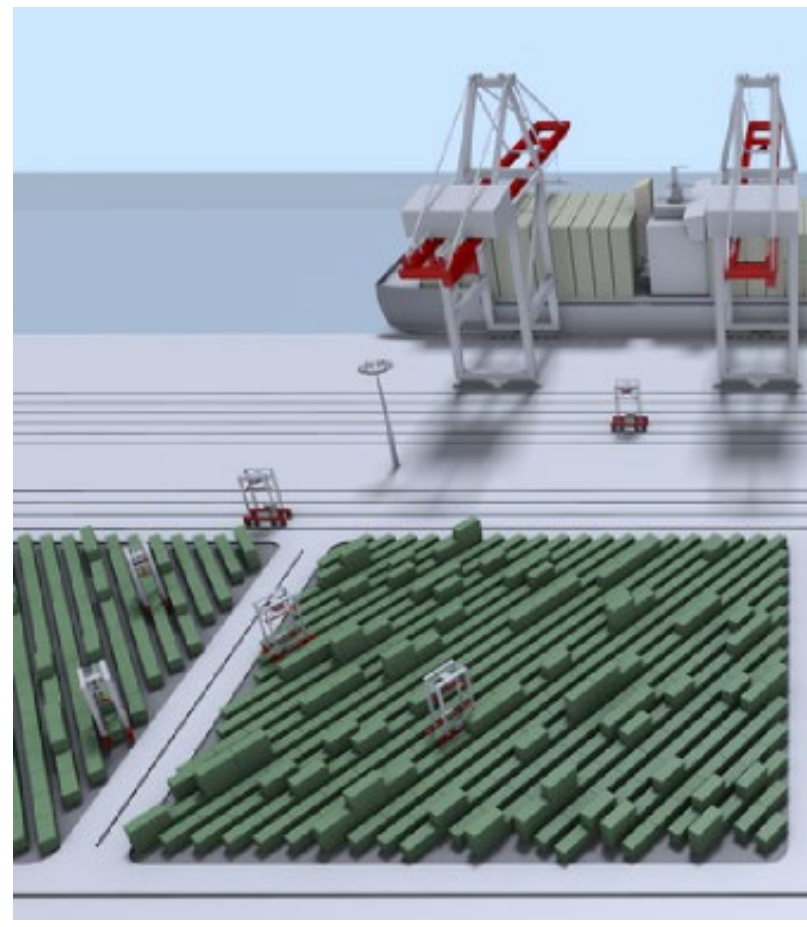

(a) Container terminal with straddle carriers

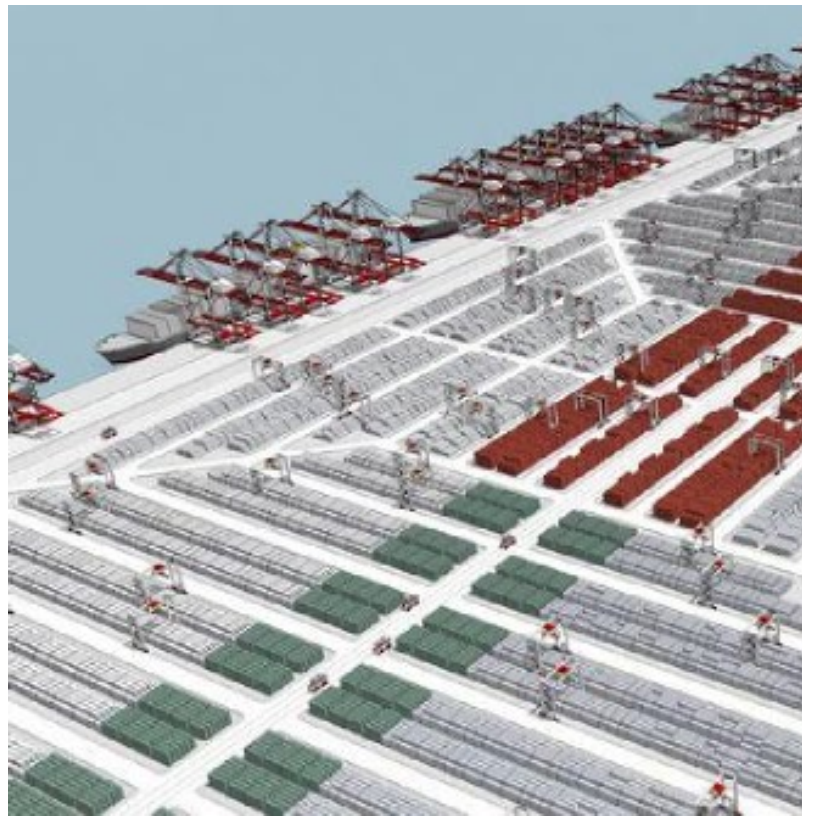

(b) Container terminal with yard cranes

Figure 4. Container terminal designs with blocks diagonal to the quay (Ivanović, 2014)

Cargotec Kalmar has recently come up with an innovative layout design. The key features in the design include an underground transportation system to separate the transshipment container movement from the vessel operation. Furthermore, containers are stacked in underground silos with solar panels on their roofs (and where drones unload the vessels). It is interesting that similar to our study, Cargotech envisions roundshaped structures (silos) for stacking containers in the future container terminal.

Higher and more compact storage systems, that are gaining ground in warehousing, are also being considered to stack containers in container terminals of the future (examples can be found in Kim et al., 2012). These new systems have high investment and operational costs, but may result in a high terminal space efficiency. Applying the appropriate design criteria and taking the correct decisions early in the project is crucial in order to meet the expected cost and performance targets.

The other studies most related to the system studied in this paper, are the ones on compact storage systems including deep-lane compact storage systems (conveyor-based and satellite-based) and live-cube compact storage systems. A few papers in the literature study compact storage systems (e.g., Stadtler 1996; Sari et al., 2005; Hu et al., 2005; Gue, 2006; Gue and Kim 2007; de Koster et al., 2008; Yu and de Koster 2009a, 2009b, 2012; Zaerpour et al., 2015, 2017). The systems studied in these papers are rectangular cuboid 
systems. Therefore, the analytical models developed cannot be applied directly to the cylindrical system studied in this paper.

The system proposed in this paper has been successfully implemented in car parks. Figure 5(a-c) shows the exterior and interior of a 20-storey car tower in Volkswagen's Autostadt in Wolfsburg, Germany. Other car towers can be found in many cities in Europe including Cesena, Stockholm, Turin and Rome. In the design by Eito and Global Inc., the car tower is located underground saving much footprint for other activities (see Figure 5d). Such a cylindrical parking system is ideally suited for use in inner city and urban settings. It solves many of the traditional problems namely, land shortage, congestion, pollution, and security through the installation of compact, circular, silos. However, more research is required to take full advantage of such a system (Wu et al., 2017). The insights and findings can be used to optimize the operations in these car towers.

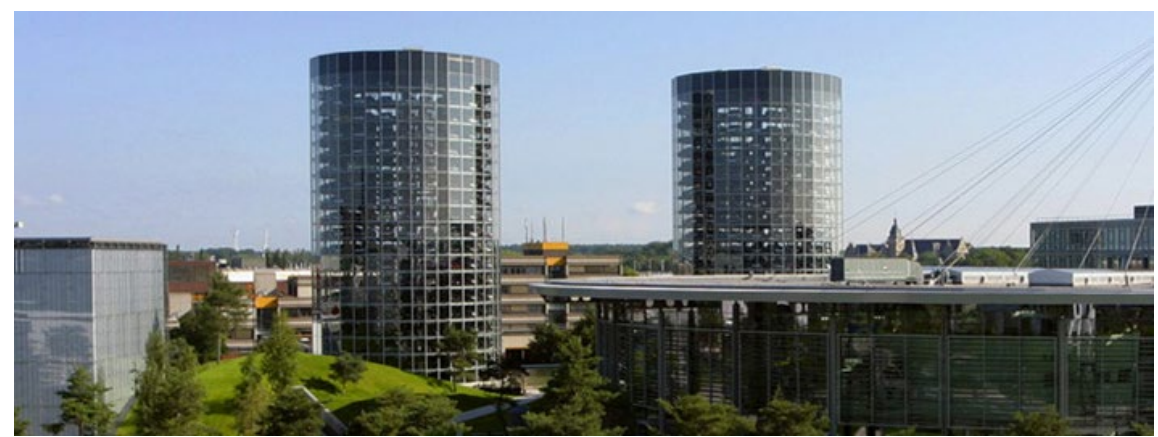

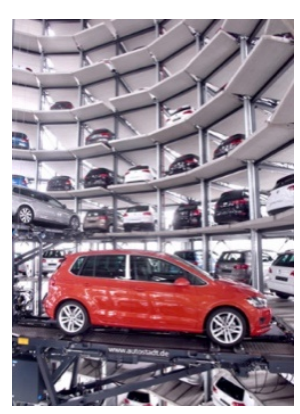

(b) Interior view (a) Exterior view

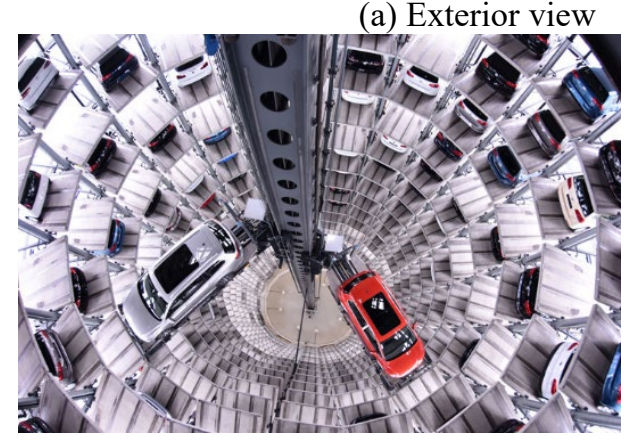

(c) Top view

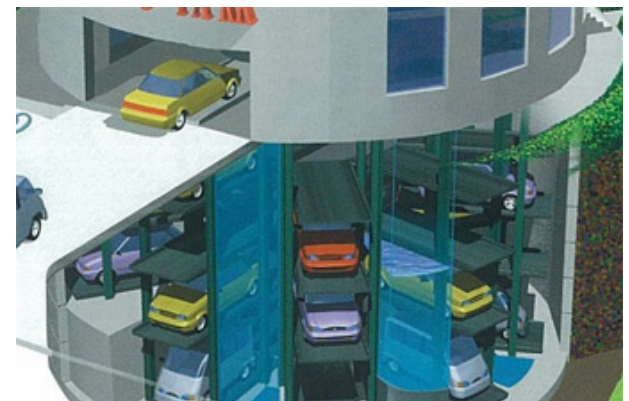

(d) Underground car tower

Figure 5. Car towers (images courtesy of Autostadt, 2016 and Eito and Global Inc., 2016)

\section{Performance evaluation and configuration optimization of a container tower}

In this section, we derive closed-form expressions for the expected retrieval time of a container tower. We then optimize the tower configuration (radius, height) in order to minimize the expected retrieval time for a given storage volume. We do this for two different types of tower design: with sequential and parallel movements of the lift in vertical and rotational directions. Section 3.1 describes the problem and 
assumptions and introduces the notations. Sections 3.2 and 3.3 calculate the expected retrieval times and optimize the tower design with sequential and parallel movements, respectively.

\subsection{Problem description, assumptions, and notations}

In order to calculate the expected retrieval time of an arbitrary request, we need to obtain the retrieval time of a container from any given storage location. It should be noted that we focus on the design performance of systems with a given storage capacity. The expected retrieval time (from an arbitrary location) is a good measure at the design phase when little operational data on container storage is available. Although we focus on the retrieval operation to derive the expected time, also inbound storage and internal relocation operations impact the performance of a container tower. However, retrieval time is the critical measure of performance, whereas the other operations can often be planned at times convenient for the system. Therefore, the analysis of such impact might be done at the operational level. Since the container tower has a cylindrical shape, the coordinates of storage locations have to be represented in a cylindrical coordinate system. In a container tower, $(\rho, \varphi, z)$ represents the coordinates of a storage location (see Figure 6) where $\rho$ refers to the radius of the tower (in meter), $\varphi$ to the rotation angle (in radian) around the $z$ axis, and $z$ indicates the height (in meter) of the storage location measured from the ground level. Each lift is dedicated to a specific portion of the total storage area. For example, if one lift is installed in the tower, the total picking surface is assigned to this lift. In such a case, the lift rotates 180 degrees (clockwise and counter clockwise) in order to access each individual location. For a container tower with three lifts, each lift is assumed to be located in the center of its zone. Therefore, , the rotational angle of each lift is 60 degrees $(\pi / 3$ radians) in clockwise and 60 degrees in counter clockwise direction (in total 120 degrees or $\pi / 3$ radians).

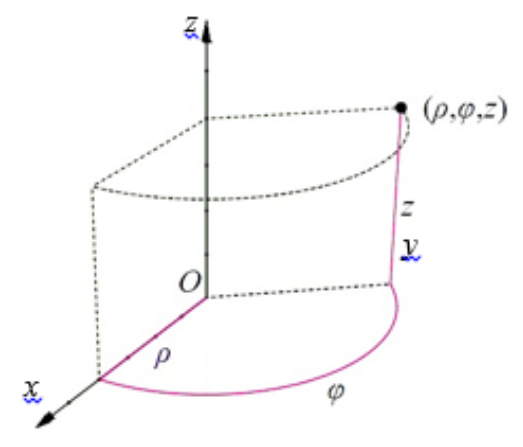

Figure 6. Cylindrical coordinates of a container tower 
Based on the coordinates of a storage location, $(\rho, \varphi, z)$, closed-form expressions for the tower travel time and the tower optimal configuration are derived in the next sections. The main notations are introduced below. Other notations will be introduced as required.

\begin{tabular}{|l|l|}
\hline Objective & expected retrieval time of an arbitrary request in a container tower (min) \\
\hline$E(R T)$ & \\
\hline Decision Variables & $\begin{array}{l}\text { radius of the container tower }(\mathrm{m}) . \text { The radius length for the container tower } \\
\text { should be greater than } 80 \mathrm{ft}(2 \times 40 \mathrm{ft} \text { to guarantee enough space for the storage } \\
\text { location and the vertical movement of the container). }\end{array}$ \\
\hline$\rho$ & height of the container tower $(\mathrm{m})$ \\
\hline$H$ & vertical average empty and loaded lift speed (m/min) \\
\hline$v_{z}$ & rotational lift speed (rad/min) \\
\hline$v_{\varphi}$ & horizontal speed of lift extension of shuttle $(\mathrm{m} / \mathrm{min})$ \\
\hline$v_{\rho}$ & number of lifts in a container tower \\
\hline$N$ & total capacity of the container tower in cubic meters \\
\hline$V$ &
\end{tabular}

\subsection{The container tower with sequential lift movements}

In this section, we first calculate the expected retrieval time of a container tower where the lifts move in vertical and rotational directions sequentially (i.e. a lift first moves to the desired level and then rotates to the desired storage location). Then, we optimize the container tower configuration (radius, height) with the objective of minimizing the expected retrieval time of an arbitrary request.

\section{Expected retrieval time calculation: sequential case}

The retrieval time of a request at location $(\rho, \varphi, z)$ can be calculated as follows

$R T(\rho, \varphi, z)=\frac{2 \varphi}{v_{\varphi}}+\frac{2 z}{v_{z}}+\frac{\rho}{v_{\rho}}$

where, $v_{\phi}$ is rotational speed of the lift $(\mathrm{rad} / \mathrm{min}), v_{z}$ is the average vertical speed of the lift $(\mathrm{m} / \mathrm{min})$, and $v_{\rho}$ is speed of the lift extension for horizontal movement ( $\mathrm{m} / \mathrm{min})$. Equation (1) consists of three components:

1. $\frac{2 \varphi}{v_{\varphi}}:$ the time needed for the lift to rotate to reach the desired retrieval position and return to the original location to reach the AGV. 
2. $\frac{2 z}{v_{z}}:$ the time needed to hoist the empty lift to reach the retrieval location assuming the lift dwells at the ground position plus the time needed for the lift to bring the container to the ground level.

3. $\frac{\rho}{v_{\rho}}$ : the time needed for the lift shuttle (or telescopic extensions) to extend, pick up the container and pull back in horizontal direction (in each move - extend or pull back, the lift shuttle travels a distance $\rho / 2$, assuming the lift shuttle connects with the container in the middle of the rotation zone; see Figure 2).

The expected retrieval time of a container depends on the storage policy (where is the container located in the tower?), the retrieval policy (does the lift carry out single cycles only, or does it combine storage with retrieval jobs?), and the dwell-point policy (where does the lift dwell when idle?). We take a conservative approach (i.e. in reality the cycle time may be shorter and the throughput higher) in calculating the cycle time using the following assumptions:

- We assume a random storage policy (every location is equally likely to contain the container needing retrieval). In reality, pre-marshaling in idle time may be possible, reducing the cycle time. Random storage requires the least data since no container information is used in determining the storage location. This assumption allows us to derive closed-form expressions for the expected retrieval time while making a fair comparison. Similar assumptions have been commonly used in the literature to obtain closed-form expressions for various storage systems at the design phase (see e.g. Hausman et al., 1976; Bozer and White, 1984; De Koster et al., 2008, Zaerpour et al, 2017).

- We consider a system with only single command cycles. In reality, the throughput of a container tower might be higher if dual command cycles are used. However, this might negatively affect the waiting time of containerships. With the new mega-containerships, there is a great sense of urgency to find ways to get ships in and out of port faster. In addition, containers arrive at the terminal some days before the arrival of their destination ships. Since the container towers are fully automated, these containers can be stacked in those towers where no retrieval is being done and they can be pre-marshalled for their final locations.

- The lifts dwell at the bottom position and always starts there. 
Assuming a random storage policy, $\varphi$ and $z$ follow a uniform distribution $(\varphi \sim U[0, \pi / \mathrm{N}], \mathrm{z} \sim U[0, \mathrm{H}])$. In addition, the horizontal distance equals $\rho$. Due to sequential movements of the lift (rotational, vertical, and horizontal), the expected retrieval time of an arbitrary container can be calculated by:

$$
E(R T)=\int_{\varphi=0}^{\pi / N} \int_{z=0}^{H}\left(\frac{2 \varphi}{v_{\varphi}}+\frac{2 z}{v_{z}}+\frac{\rho}{v_{\rho}}\right) f(\varphi, z) d \varphi d z=\frac{\pi}{N v_{\varphi}}+\frac{H}{v_{z}}+\frac{\rho}{v_{\rho}},
$$

Where, $N$ represents the number of lifts used in the tower.

\section{General model and optimization: sequential case}

The results obtained in the previous section can be used to optimize the system configuration by minimizing the expected retrieval time. To optimize the dimensions of a container tower with $N$ lifts, we propose the following nonlinear model:

$$
\min E(R T)
$$

subject to:

$$
\pi \rho^{2} \mathrm{H}=V \text {, }
$$

Decision variables: $\quad \rho>0, H>0$,

where, $E(R T)$ is the expected retrieval time of a container tower with capacity $V$, radius $\rho$, and height $H$.

We now optimize the height $H$ and radius $\rho$ (both in meter) of a container tower for a given storage capacity $V$ (in cubic meter).

Since the system has the shape of a cylinder, $V=\pi \rho^{2} \mathrm{H}$ and consequently we can replace $H$ with $\frac{V}{\pi \rho^{2}}$. Thus, the objective function can be written as a function of $\rho$,

$$
E(R T)=\frac{\pi}{N v_{\varphi}}+\frac{V}{\pi \rho^{2} v_{z}}+\frac{\rho}{v_{\rho}}
$$

The optimal value of $\rho$, minimizing the objective function, can be obtained by the first order condition (see e.g. Hausman et al., 1976; De Koster et al., 2008, Zaerpour et al. 2017),

$$
\frac{\partial E(R T)}{\partial \rho}=\frac{1}{v_{\rho}}-\frac{2 V}{\pi v_{z} \rho^{3}}=0
$$


Table 1 gives the optimal closed-form formulas for $\rho, H$, and $E(R T)$. The second derivative test proves that the objective function is convex and therefore the optimal height and radius give the minimum objective value.

Table 1. Optimal $\rho, H$, and $E(R T)$ of a container tower for any given $V\left(\mathrm{~m}^{3}\right)$ and number of lifts $N$

\begin{tabular}{lll}
\hline Optimal radius in meter $\left(\rho^{*}\right)$ & Optimal height in meter $\left(\boldsymbol{H}^{*}\right)$ & $\begin{array}{l}\text { Optimal expected retrieval time in } \\
\min \left(\boldsymbol{E}\left(\boldsymbol{R} \boldsymbol{T}^{*}\right)\right)\end{array}$ \\
\hline$\frac{\left(\frac{2}{\pi}\right)^{1 / 3} v_{\rho}{ }^{1 / 3}}{v_{z}{ }^{1 / 3}} V^{1 / 3}$ & $\frac{v_{z}^{2 / 3}}{2^{2 / 3} \pi^{1 / 3} v_{\rho}^{2 / 3}} V^{1 / 3}$ & $\frac{\pi}{N v_{\varphi}}+\frac{3 V^{1 / 3}}{2^{2 / 3} \pi^{1 / 3} v_{z}^{1 / 3} v_{\rho}^{2 / 3}}$ \\
\hline
\end{tabular}

Based on the results in Table 1, we make the following observations:

Observation 1. The optimal radius and height are not influenced by the number of lifts used in the tower. In addition, unlike the horizontal and vertical speeds of the lift, the rotational speed of the lift does not impact the optimal radius and height of the tower. The reason is that the rotational speed of the lift is measured in radians per minute and the angle rotated by the lift per minute is not impacted by the radius of the tower.

Observation 2. By increasing the number of lifts, the expected rotational time of the lift decreases proportionately. However, the expected vertical and horizontal time of the lift does not change. In addition, by increasing the volume of the tower, the optimal radius, height and expected retrieval time increase but at a lower rate (proportional to $V^{1 / 3}$ ).

Observation 3. As the rotational, vertical, and horizontal speeds decrease, the minimum expected retrieval time, $E(R T)$, increases. In addition, a change in the vertical (or horizontal) speed has an opposite effect on the optimal radius (or height). For example, an increase in horizontal speed decreases the optimal height of the tower while an increase in vertical speed increases the optimal height.

\subsection{The container tower with parallel lift movements}

In this section, we consider a container tower where the lift(s) moves in vertical and rotational directions in parallel (i.e. the lift moves to the desired level while simultaneously rotates to the column of the desired storage location). This design is typically possible and has been implemented in car towers (see e.g. Figure 5(c) and Autostadt, 2016). However, for container towers the realization depends on the tower construction. We first calculate the expected retrieval time of the container tower. Then, we optimize the container tower 
configuration (radius, height) with the objective of minimizing the expected retrieval time of an arbitrary request.

\section{Expected retrieval time calculation: parallel case}

The retrieval time of a request at location $(\rho, \varphi, z)$ can be calculated as follows

$R T(\rho, \varphi, z)=2 \operatorname{Max}\left\{\frac{\varphi}{v_{\varphi}}, \frac{z}{v_{z}}\right\}+\frac{\rho}{v_{\rho}}$

where, $v_{\varphi}$ is rotational speed of the lift ( $\left.\mathrm{rad} / \mathrm{min}\right), v_{z}$ is the average speed of the lift for vertical movement, $(\mathrm{m} / \mathrm{min})$, and $v_{\rho}$ is speed of the lift extension for horizontal movement $(\mathrm{m} / \mathrm{min})$. Equation (7) consists of two components:

1. $v_{\varphi} \quad v_{z}$ : Since the lift rotates and moves vertically at the same time, the maximum time of $2 \operatorname{Max}\left\{\frac{\varphi}{v_{\varphi}}, \frac{z}{v_{z}}\right\}$ these two moves has to be considered. The maximum value has to be doubled as the lift needs to rotate and move back to its original location on the ground level to reach the AGV.
2. $\frac{\rho}{v_{\rho}}$ : the time needed for the lift shuttle or telescopic extensions to extend, pick up the container and pull back in horizontal direction.

The assumptions are similar to the case with sequential movement (see section 3.2). Assuming a random storage policy, $\varphi$ and $z$ follow a uniform distribution $(\varphi \sim U[0, \pi / \mathrm{N}], \mathrm{z} \sim U[0, \mathrm{H}])$. In addition, the horizontal distance always equals $\rho$. Thus, we first calculate the expected retrieval time for the rotational and vertical movements. Two different cases are possible: 1) $\frac{\pi}{N v_{\varphi}} \leq \frac{H}{v_{z}}$ or 2) $\frac{\pi}{N v_{\varphi}} \geq \frac{H}{v_{z}}$. Let us start with case $1\left(\frac{\pi}{N v_{\varphi}} \leq \frac{H}{v_{z}}\right)$. Let $F(t)$ represent the probability that the travel time to location $(\varphi, z)$ is less than or equal to $t$ (cumulative distribution function). Then,

$$
F(t)=P(T \leq t)=P\left(\frac{\varphi}{v_{\varphi}} \leq t\right) \times P\left(\frac{z}{v_{z}} \leq t\right)
$$

Then, we can write,

$$
P\left(\frac{\varphi}{v_{\varphi}} \leq t\right)=\left\{\begin{array}{ll}
t N v_{\varphi} / \pi & 0 \leq t \leq \pi / N v_{\varphi} \\
1 & \pi / N v_{\varphi} \leq t \leq H / v_{z}
\end{array},\right.
$$




$$
P\left(\frac{z}{v_{z}} \leq t\right)=t v_{z} / H \quad 0 \leq t \leq H / v_{z} .
$$

As a result, the cumulative distribution can be obtained:

$$
F(t)=\left\{\begin{array}{ll}
t^{2} N v_{\varphi} v_{z} / \pi H & 0 \leq t \leq \pi / N v_{\varphi} \\
t v_{z} / H & \pi / N v_{\varphi} \leq t \leq H / v_{z}
\end{array} .\right.
$$

Then, we can calculate the probability density function, $f(t)$ :

$$
f(t)=\left\{\begin{array}{ll}
2 t N v_{\varphi} v_{z} / \pi H & 0 \leq t \leq \pi / N v_{\varphi} \\
v_{z} / H & \pi / N v_{\varphi} \leq t \leq H / v_{z}
\end{array} .\right.
$$

Now, we can calculate the expected retrieval time of an arbitrary request as follows:

$$
\begin{aligned}
& E(R T)=2 E(\varphi, z)+E(\rho) \\
& E(\varphi, z)=\int_{t=0}^{H / v_{z}} t f(t) d t=\int_{t=0}^{\pi / N v_{\varphi}} t f_{1}(t) d t+\int_{t=\pi / N_{\varphi}}^{H / v_{z}} t f_{2}(t) d t=\int_{t=0}^{\pi / N v_{\varphi}} 2 t^{2} N v_{\varphi} v_{z} / \pi H d t+\int_{t=\pi / N v_{\varphi}}^{H / v_{z}} t v_{z} / H d t=\frac{H}{2 v_{z}}+\frac{\pi^{2} v_{z} v_{\varphi}^{2}}{6 H N^{2}} \\
& E(R T)=\frac{H}{v_{z}}+\frac{\pi^{2} v_{z} v_{\varphi}^{2}}{3 H N^{2}}+\frac{\rho}{v_{\rho}}
\end{aligned}
$$

The above Equation gives the expected retrieval time of an arbitrary request where $\frac{\pi}{N v_{\varphi}} \leq \frac{H}{v_{z}}$. In case,

$$
\begin{array}{ll}
\frac{\pi}{N v_{\varphi}} \geq \frac{H}{v_{z}}, \text { the expected retrieval time can be calculated s } \\
E(R T)=\frac{H}{v_{z}}+\frac{\pi^{2} v_{z} v_{\varphi}^{2}}{3 H N^{2}}+\frac{\rho}{v_{\rho}}, & \text { if } \frac{\pi}{N v_{\varphi}} \leq \frac{H}{v_{z}}, \\
E(R T)=\frac{\rho}{v_{\rho}}+\frac{\frac{\pi}{N}+\frac{H^{2} N}{3 \pi v_{z}^{2}}}{v_{\varphi}}, & \text { if } \frac{\pi}{N v_{\varphi}} \geq \frac{H}{v_{z}} .
\end{array}
$$

\section{General model and optimization: parallel case}

The results obtained in the previous section can be used to optimize the system configuration by minimizing the expected retrieval time. To optimize the dimensions of a container tower with $N$ lifts, we propose the following nonlinear model: 


$$
\min E(R T)
$$

subject to:

$$
\pi \rho^{2} \mathrm{H}=V \text {, }
$$

Decision variables: $\quad \rho>0, H>0$,

where, $E(R T)$ is the expected retrieval time of a container tower with capacity $V$, radius $\rho$, and height $H$. We now optimize the height $H$ and radius $\rho$ (both in meter) of a container tower for a given storage capacity $V$ (in cubic meter). Since the system has a cylindrical shape, $V=\pi \rho^{2} \mathrm{H}$ and consequently we can replace $H$ with $\frac{V}{\pi \rho^{2}}$. As different expected retrieval time formulas are obtained for the two cases $\left(\frac{\pi}{N v_{\varphi}} \leq \frac{H}{v_{z}}\right.$ and $\frac{\pi}{N v_{\varphi}} \geq \frac{H}{v_{z}}$, we need to solve the nonlinear model for each case. The procedure is similar to the one discussed in section 3.2 and is skipped here. Table 2 gives the optimal closed-form formulas for $\rho, H$, and $E(R T)$ for the case $\frac{\pi}{N v_{\varphi}} \geq \frac{H}{v_{z}}$. For the case $\frac{\pi}{N v_{\varphi}} \leq \frac{H}{v_{z}}$, optimal closed-form formulas for $\rho, H$, and $E(R T)$ are given in online Appendix A.

$\underline{\text { Table 2. Optimal } \rho^{*}, H^{*}, E\left(R T^{*}\right) \text { of a container tower with parallel design and for case } \frac{\pi}{N v_{\varphi}} \geq \frac{H}{v_{z}}}$

\section{Parameter Optimal closed-form expression}

Optimal radius in meter $\left(\rho^{*}\right) \quad \frac{2^{2 / 5} N^{1 / 5} v_{\rho}^{1 / 5}}{3^{1 / 5} \pi^{3 / 5} v_{z}^{2 / 5} v_{\varphi}^{1 / 5}} V^{2 / 5}$

Optimal height in meter $\left(H^{*}\right)$

$$
\frac{3^{2 / 5} \pi^{1 / 5} v_{z}^{4 / 5} v_{\varphi}^{2 / 5}}{2^{4 / 5} N^{2 / 5} v_{\rho}^{2 / 5}} V^{1 / 5}
$$

Optimal expected retrieval time in min $\left(E\left(R T^{*}\right)\right)$

$$
\frac{\pi}{N v_{\varphi}}+\frac{5 N^{1 / 5}}{23^{1 / 5}(2 \pi)^{3 / 5} v_{z}^{2 / 5} v_{\rho}^{4 / 5} v_{\varphi}^{1 / 5}} V^{2 / 5}
$$

Based the results in Table 2 and online Appendix A, we make the following observations:

Observation 1. The closed-form expressions obtained for $H^{*}, \rho^{*}, E\left(R T^{*}\right)$ for the two complementary cases $\frac{\pi}{N v_{\varphi}} \leq \frac{H}{v_{z}}$ and $\frac{\pi}{N v_{\varphi}} \geq \frac{H}{v_{z}}$ are different. This is different from the rectangular storage systems such as the ones in the warehousing literature where it suffices to consider only one case (e.g. see Hausman et al., 1976; De Koster et al., 2008, Zaerpour et al., 2017). For instance, Hausman et al. (1976) aim to obtain the optimal 
dimensions of an automated storage and retrieval system (AS/RS) with a rectangular shape. In their papers, the authors, without loss of generality, assume that the length of the system in horizontal direction is larger than the one in vertical direction and obtain the expected retrieval time for only this case.

Observation 2. At the boundary of the case condition (i.e. when $\frac{\pi}{N v_{\varphi}}=\frac{H}{v_{z}}$ ), the closed form expressions $\left(\rho^{*}, H^{*}\right.$, and $\left.E\left(R T^{*}\right)\right)$ of both cases result in the same formulas. This is expected and has been used in order to evaluate the accuracy of the obtained closed-form expressions.

\section{Cost comparison of container tower and container block}

In this section, we compare a container tower with a container block for investment and operational costs. In section 4.1, we derive closed-form expressions in order to compare the investment cost of a container tower and a container block. In section 4.2, we use a nonlinear model in order to obtain the optimal configuration (radius, height) of container tower which minimizes its investment cost.

\subsection{Investment and operational cost estimation for a container tower}

In order to fairly compare the total investment cost of a container tower with a container block, both systems are assumed to have the same storage capacity. In addition, we assume both container tower and container block are greenfield projects where the required land needs to be reclaimed from sea (e.g. Rotterdam's Maasvlakte 2 and Abu Dhabi's KPIZ). We define the following parameters:

$c_{l}: \quad$ Land reclamation cost per square meter.

$c_{t}$ : Average investment in material handling technology (automated stacking cranes, rails) per storage location in a container block.

$c_{t}^{\prime}$ : Average investment in material handling technology (lifts, shuttles, storage racks) per storage location in a container tower.

$\varepsilon \quad$ Average footprint (in square meter) required for each storage location in a container block.

$\varepsilon^{\prime} \quad$ Average footprint (in square meter) required for each storage location in a container tower.

$n \quad$ Design storage capacity in number of storage locations

It should be noted that the land reclamation cost for a tower system, which needs to be constructed with many tiers, may be higher than that for a traditional block. However, we here assume that the land reclamation cost per square meter for both systems is the same. The investment in technology for container handling in a container block is generally lower than the one for a container tower, i.e. $\dot{c}_{t}>c_{t}$. The 
technology cost ratio, $\gamma(\gamma>1)$, shows how expensive a container tower is compared to a container block in terms of material handling technology. The technology cost ratio equals

$$
\gamma=\frac{c_{t}^{\prime}}{c_{t}} .
$$

For a terminal with container blocks, each storage location needs on average a larger footprint than a next generation terminal, i.e. $\varepsilon>\varepsilon^{\prime}$ (stacking height is lower in a container block than in a container tower). The footprint ratio, $\varphi$, can be defined as follows $(\varphi>1)$,

$$
\varphi=\frac{\varepsilon}{\varepsilon^{\prime}}
$$

The total investment for a container block $\left(c_{\text {total }}\right)$ and for a container tower $\left(\dot{c}_{\text {total }}\right)$ can be expressed as follows,

$$
\begin{aligned}
c_{\text {total }} & =c_{l} \varepsilon n+c_{t} n, \\
c_{\text {total }} & =c_{l} \varepsilon^{\prime} n+\dot{c}_{t} n .
\end{aligned}
$$

$c_{\text {ave }}\left(=c_{\text {total }} / n\right)$ and $\dot{c}_{\text {ave }}\left(=\dot{c}_{\text {total }} / n\right)$ represent the average investment cost per storage location for a container block and a container tower, respectively. We define $c_{i n c}$ as the incremental cost, which is the average investment cost for a container block minus the average investment cost for a container tower, i.e. $c_{\text {inc }}=c_{\text {ave }}-\dot{c}_{\text {ave }}$. Thus, if $c_{\text {inc }}>0$, a container tower requires lower investment than a container block $\left(c_{a v e}>\dot{c}_{\text {ave }}\right)$ and vice versa. Using Equations (20-23), the incremental cost, $c_{\text {inc }}$, can be presented as follows,

$$
c_{\text {inc }}=c_{\text {cre }}-c_{\text {cre }}^{\prime}=c_{l} \varepsilon\left(1-\frac{1}{\varphi}\right)+c_{t}(1-\gamma),
$$

where $\varphi$ and $\gamma$ are the footprint ratio and technology cost ratio, respectively.

In addition to the investment cost, the variable operational costs (i.e. not investment related) need to be considered. Let us define the following parameters:

$c_{\text {opr }}$ : Average annual variable operational costs per storage location for a container block (maintenance of equipment, energy, direct and indirect labor)

$\dot{c}_{\text {opr }}: \quad$ Average annual variable operational costs per storage location for a container tower

$\tau_{\text {max }}$ : Maximum acceptable payback period, this is the maximum period of time acceptable for the investor for the return on an investment 
$S_{\text {inc }}$ represents the difference between the average operational costs per storage location for a container block and a container tower $\left(s_{\text {inc }}=c_{\text {opr }}-\dot{c}_{\text {opr }}\right)$.

Table 3. summarizes the comparison between a container block and a container tower in terms of investment and operational costs. The table shows which system has to be selected depending on incremental investment cost, $c_{i n c}$ and incremental operational cost, $s_{i n c}$. In situations where further analysis is required, i.e. $c_{\text {inc }}>0 \wedge s_{\text {inc }}<0$ or $c_{\text {inc }}<0 \wedge s_{\text {inc }}>0$ the net present value (NPV) of incremental operational cost, $s_{\text {inc }}$, over the acceptable payback period, $\tau_{\max }$ has to be calculated as follows:

$$
\operatorname{NPV}\left(i, \tau_{\max }\right)=\sum_{t=0}^{\tau_{\max }} \frac{s_{i m c}}{(1+i)^{t}}
$$

where, $i$ is the discount rate and $t$ is the time period. Then, the net present value of incremental operational cost $\left(\mathrm{NPV}\left(i, \tau_{\max }\right)\right)$ needs be compared with the incremental investment cost $\left(c_{\text {inc }}\right)$. We essentially investigate whether the additional investment in a container tower can be compensated by the savings in operational costs (e.g. less direct and indirect labor costs) during the payback period. If $c_{i n c}+N P V>0$, then implementing a container tower will result in lower total costs, and if $c_{i n c}+N P V<0$, implementing a container block will result in lower total costs.

Table 3. Cost comparison of container block and container tower based on incremental investment cost, $c_{i n c}$ and incremental operational cost, $s_{i n c}$

\begin{tabular}{l|ll}
\hline & $c_{\text {inc }}>0$ & $c_{\text {inc }}<0$ \\
\hline$s_{\text {inc }}>0$ & Container tower is cheaper & Further analysis is required \\
$s_{\text {inc }}<0$ & Further analysis is required & Container block is cheaper \\
& & \\
\hline $\begin{array}{l}\text { If Further } \\
\begin{array}{l}\text { analysis is } \\
\text { required }\end{array}\end{array}$ & $c_{\text {inc }}+N P V>0$ & selected terminal type \\
\hline
\end{tabular}

\subsection{Investment minimization of the container tower}

In this section, we obtain the optimal configuration (radius, height) of a container tower with the objective of minimizing its investment cost while a given performance (response time) and volume can be achieved. We consider the design with the sequential movement of the lift depicted in Figure 2. In order to formulate the cost minimization model, we use the results obtained in previous sections. The expected retrieval time 
closed-form expression is obtained in section 3.2 and the investment cost closed-form expression is obtained in section 4.1. The investment cost minimization model is a nonlinear model which can be presented as follows:

$\min c_{l} \varepsilon^{\prime} n+\dot{c}_{t} n$

subject to:

$$
\begin{aligned}
& \frac{\pi}{N v_{\varphi}}+\frac{H}{v_{z}}+\frac{\rho}{v_{\rho}} \leq T \\
& \pi \rho^{2} \mathrm{H}=V,
\end{aligned}
$$

Decision variables: $\quad \rho>0, \mathrm{H}>0$,

where, $T$ is the maximum allowed expected retrieval time of the container tower (min) and $\rho$ and $H$ are the decision variables representing the radius and height of the tower $(\mathrm{m})$. In addition, $c_{l}$ is the land reclamation cost per square meter, $\varepsilon^{\prime}$ is the average footprint $\left(\mathrm{m}^{2}\right)$ required for each storage location in a container tower, $n$ is the design storage capacity in number of storage locations, $c^{\prime}{ }_{t}$ is the average investment in material handling technology (lifts, shuttles, storage racks) per storage location in a container tower, $N$ is the number of lifts in the tower, $v_{\varphi}$ is rotational speed of the lift $(\mathrm{rad} / \mathrm{min}), v_{z}$ is the average speed of the lift for vertical movement $(\mathrm{m} / \mathrm{min})$, and $v_{\rho}$ is speed of the lift extension for horizontal movement $(\mathrm{m} / \mathrm{min})$, and $V$ is the volume of container tower $\left(\mathrm{m}^{3}\right)$.

The objective is to minimize the total investment of a container tower (Eq. (26)). Constraint (27) guarantees that the expected retrieval time of the container tower does not violate the maximum allowed time. Constraint (28) ensures that the given volume is achieved.

Since $\varepsilon^{\prime}$ is the average footprint $\left(\mathrm{m}^{2}\right)$ required for each storage location in a container tower and due to circular shape of the tower, we have: $\varepsilon^{\prime}=\pi \rho^{2} / n$. The objective function can be written as follows:

$$
\min c_{l} \pi \rho^{2}+\dot{c}_{t} n
$$

As the objective is a function of only the radius $(\rho)$, a smaller value of the radius will decrease its value. Thus, we need to find the smallest $\rho$ which satisfies the constraints (27-28). In addition, since the tower has a cylindrical shape, $V=\pi \rho^{2} H$ and consequently we can replace $H$ with $\frac{V}{\pi \rho^{2}}$. Thus, the constraint (27) can be written as a function of $\rho$, 


$$
\frac{\pi}{N v_{\varphi}}+\frac{V}{\pi \rho^{2} v_{z}}+\frac{\rho}{v_{\rho}} \leq T
$$

We need to solve $\frac{\pi}{N v_{\varphi}}+\frac{V}{\pi \rho^{2} v_{z}}+\frac{\rho}{v_{\rho}}=T$ in order to obtain different values of $\rho$. This equation can be reformulated as follows in which the numerator is a cubic function with the general for $a x^{3}+b x^{2}+c x+d=0$.

$$
\frac{N \pi v_{z} v_{\varphi} \rho^{3}+\left(\pi^{2} v_{z} v_{\rho}-N \pi T v_{z} v_{\rho} v_{\varphi}\right) \rho^{2}+N V v_{\rho} v_{\varphi}}{N \pi \rho^{2} v_{z} v_{\rho} v_{\varphi}}=0
$$

As all of the coefficients $a, b, c$, and $d$ of the cubic equation are real numbers, it has at least one real root. All of the roots of the cubic equation can be found algebraically by using the discriminant. The numbers of real and complex roots can be determined by the discriminant of the cubic equation. The general form of the discriminant of a cubic equation is $\Delta=18 a b c d-4 b^{3} d+b^{2} c^{2}-4 a c^{3}-27 a^{2} d^{2}$. Since, in our case, the discriminant is less than zero $(\Delta<0)$, the cubic function has one real root and two non-real complex conjugate roots (see e.g. Dummit and Foote, 1998). Note that in the numerical analysis, the non-real complex expressions might have a very small imaginary part (virtually zero) and thus the real part of the complex number can be considered as potential optimal value for the radius of the tower. The three closedform expressions for the optimal radius are shown in online Appendix B. In the numerical analysis, among these solutions, the radius with the smaller value will result in the lowest investment that can achieve the given response time.

\section{Numerical results on performance and cost analysis}

In this section we numerically evaluate the results obtained in sections 3 and 4. In section 5.1, we present the closed-form expressions obtained from the literature in order to calculate the throughput of a container block with a single automated stacking crane. Section 5.2 compares the performance of a container tower and a container block for a realistic range of design parameters. Section 5.3 compares the cost of a container tower and container block. Finally, section 5.4 obtains the optimal configuration of a container tower for a given expected response time and storage volume. 


\subsection{Average retrieval time with an automated stacking crane in a container block}

To compare the container tower system performance with that of a container block, the average retrieval time of arbitrary container in a container block of the same capacity needs to be calculated. We use the formulas developed by Kim (1997) and Vis (2006) to calculate the average retrieval time of an arbitrary container in a container block with automated stacking crane (ASC).

The average hoisting time of container in a block with a given number of tiers can be estimated using the following equation:

Average hoisting time for $A S C=\frac{\left(\text { Ave }_{T}+1\right) \times \text { height of a container }}{2(\text { hoisting speed of ASC when full })}+\frac{\left(\text { Ave }_{T}+1\right) \times \text { height of acontainer }}{2(\text { hoisting speed of ASCwhenempty })}$,

where, $A v e_{T}$ is the average number of tiers in a block.

To calculate the average number of reshuffles required per retrieval in a block we use the following equation based on Kim (1997):

$$
\text { Average \# reshuffles needed per retrieval }=\frac{A v e_{T}-1}{2} \text {. }
$$

Following Vis (2006) and assuming that every reshuffled container is moved to a location in the same bay and trolley dwells at the corner position, for each reshuffle, the ASC needs to travel half of the container block rows to move the container and half of the container block rows to return the original location (see Figure 7). Thus, the average total reshuffling time for an arbitrary retrieval request is:

Average reshuffletime for $A S C=$ Average \# reshuffles needed $\left(\frac{\text { width of block }}{\text { Trolley speed of } A S C}+\right.$ Average hoisting time of acontainer $)$.

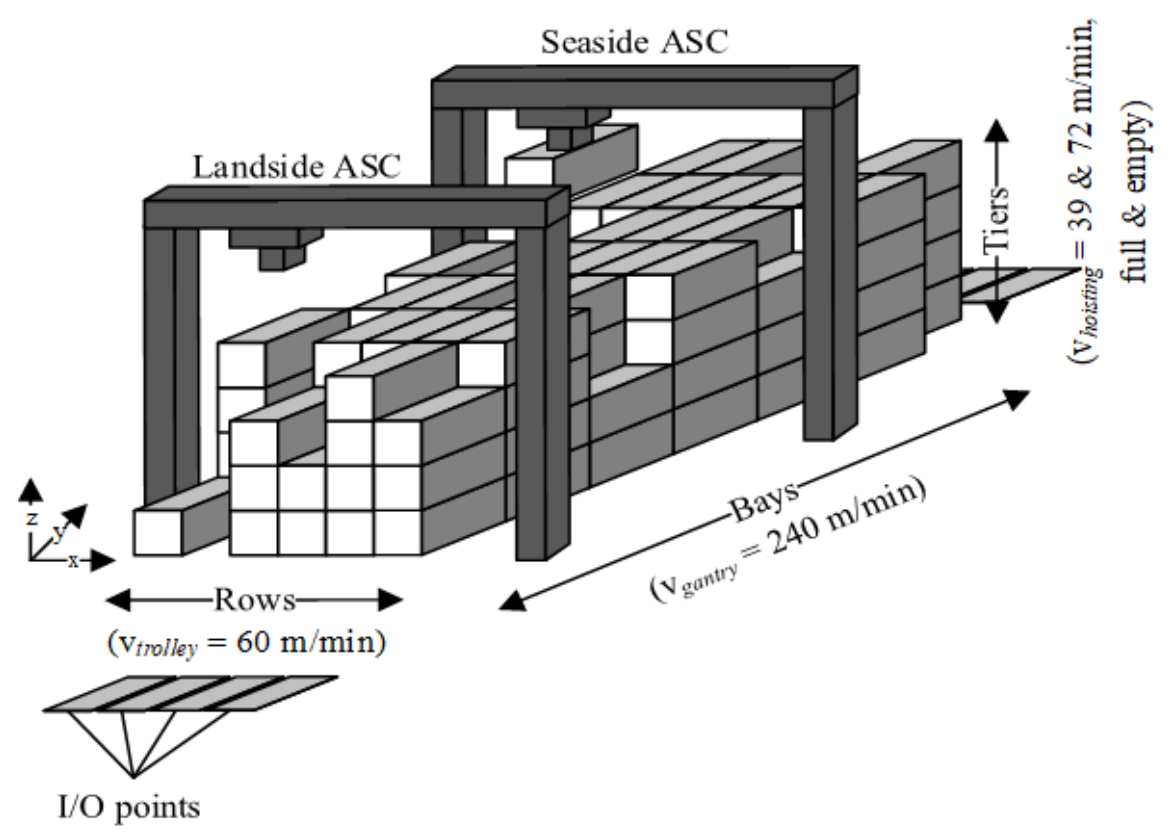

Figure 7. Layout of a container block with two automated stacking cranes 
Assuming a random storage policy and the ASC dwelling at an I/O point when idle, the average horizontal travel time of an ASC (gantry and trolley) is the time the ASC needs to travel the block's half-length and half-width to pick up the container plus the same time to return to the $\mathrm{I} / \mathrm{O}$ point.

Consequently, the average total travel time required to retrieve a requested container equals:

Averagetotal travel time for ASC = Average hoisting time + Averagereshuffetime + Average horizontal time .

In addition, the storage density for a container tower and container block can be calculated. The storage density is equal to the number of TEUs stored per area unit for container tower and container block. The storage density for both systems can be calculated by:

Storage Density $=$ \#TEUs stored in a given land profile / land area .

\subsection{Performance evaluation of a container tower versus a container block}

In this section, we use the closed-form expressions obtained in section 3.2 to obtain the optimal configuration of a container tower for a given volume and footprint (we consider the design with sequential lift movements and three lifts). We then calculate the expected retrieval time of a container tower using the closed-form expressions in section 3.2. In addition, we use the closed-form expressions in section 5.1 to calculate the expected retrieval time of a container block. The input parameters of the container tower and container block are shown in online Appendix C (given volume: $331750 \mathrm{~m}^{3}$, given footprint, $5025 \mathrm{~m}^{2}$ ).

In order to calculate the optimal radius for a given volume $\left(331750 \mathrm{~m}^{3}\right)$, we use the closed-form expression in Table 1 (see section 3.2). Thus, we can write:

$$
\rho=\frac{\left(\frac{2}{\pi}\right)^{1 / 3} v_{\rho}^{1 / 3}}{v_{z}^{1 / 3}} V^{1 / 3}=\frac{\left(\frac{2}{\pi}\right)^{1 / 3} 110^{1 / 3}}{60^{1 / 3}} 331750^{1 / 3}=72.8 \mathrm{~m}
$$

However, for the given footprint $\left(5025 \mathrm{~m}^{2}\right)$ the optimal radius cannot be realized, as it requires a too large footprint. Thus, we need to find the largest radius which does not violate the footprint limit and which allows to store at least one forty-foot container and leaves space for the lift and shuttle. As a results, we have, $\pi \rho^{2}=5025$ and $\rho^{*}=40 \mathrm{~m}$. We can then obtain, the optimal height and expected retrieval time as follows:

$$
H^{*}=\frac{V}{\pi \rho^{* 2}}=\frac{331750}{\pi 40^{2}}=66 \mathrm{~m} \text { and } E(R T)=\frac{\pi}{N v_{\varphi}}+\frac{H}{v_{z}}+\frac{\rho}{v_{\rho}}=\frac{\pi}{3 \times 2}+\frac{66}{60}+\frac{40}{110}=1.98 \mathrm{~min}
$$

. The annual

throughput of the container tower can be calculated as follows (For the sake of illustration and without loss 
of generality, for both the container tower and the container block, we have assumed 16 hours per day and 260 operating days per year, with $80 \%$ system availability):

Throughput Capacity of a Container Tower $=\frac{16 \times 60 \times 260 \times 0.8 \times 1.68}{\left(\frac{1.98}{3}\right)}=503,677$ TEU $/$ year

We now compare the performance (throughput: TEU/year) of a container tower and a container block of the same storage capacity. We here consider a typical configuration of a container block with two ASCs, one ASC dedicated to the landside and the other one to the seaside movements. Table 4 shows the results for varying storage capacity. For the container tower, the instance with 600 locations is the one with the optimal radius and height obtained above. In the other instances, the height (number of levels) of the container tower is varied while the radius is not. The details of calculation for the container block are shown in online Appendix C. In addition, Table 5 presents the performance of the container tower for varying number of lifts and compares the results with the container block of the same storage capacity ( 600 storage locations).

Table 4: Comparison of container tower and container block for varying number of storage locations

\begin{tabular}{llllll}
\hline $\begin{array}{l}\text { No. of } \\
\text { storage } \\
\text { locations }\end{array}$ & $\begin{array}{l}\text { Throughput } \\
\text { of container } \\
\text { tower } \\
\text { (TEU/year) }\end{array}$ & $\begin{array}{l}\text { Throughput } \\
\text { of container } \\
\text { block }\end{array}$ & Imp (\%) & $\begin{array}{l}\text { Number of } \\
\text { (TEUels of } \\
\text { (Tontainer tower) }\end{array}$ & $\begin{array}{l}\text { Dimensions of } \\
\text { container block } \\
\text { (bays } \times \text { rows } \times \text { tiers) }\end{array}$ \\
\hline 150 & 864039 & 396922 & $117.69 \%$ & 5 & $8 \times 5 \times 4$ \\
450 & 585006 & 266735 & $119.32 \%$ & 15 & $23 \times 5 \times 4$ \\
600 & 503677 & 231328 & $117.73 \%$ & 20 & $30 \times 5 \times 4$ \\
1050 & 355436 & 161074 & $120.67 \%$ & 35 & $53 \times 5 \times 4$ \\
1650 & 255265 & 115372 & $121.25 \%$ & 55 & $83 \times 5 \times 4$ \\
\hline
\end{tabular}

*Imp: shows how much improvement in throughput can be achieved for each instance by utilizing container tower instead of container block $\left(T P_{\text {tower }}-T P_{\text {block }}\right) / T P_{\text {block }}$

Table 5: comparison of container tower and container block for varying number of lifts ${ }^{*}$

\begin{tabular}{lll}
\hline $\begin{array}{l}\text { Number of } \\
\text { lifts }\end{array}$ & $\begin{array}{l}\text { Throughput of container } \\
\text { tower (TEU/year) }\end{array}$ & Imp(\%)
\end{tabular}

\begin{tabular}{|c|c|c|c|}
\hline 1 & 110177 & $-52.37 \%$ & N/A \\
\hline 2 & 296903 & $28.35 \%$ & $169.48 \%$ \\
\hline 3 & 503677 & $117.73 \%$ & $69.64 \%$ \\
\hline 4 & 718624 & $210.65 \%$ & $42.68 \%$ \\
\hline 5 & 937702 & $305.36 \%$ & $30.49 \%$ \\
\hline
\end{tabular}


We make the following observations:

Observation 1. The results in Table 4 show that the container tower can outperform the container block in terms of annual throughput. This is because 1) in a container tower each container can be accessed individually without any need for reshuffling, 2) the lifts in a container tower can operate simultaneously without any interference, and 3) on average, ASCs need to travel longer horizontally compared to the lifts in a container tower.

Observation 2. By increasing the storage capacity, the throughput performance of both the container tower and the container block declines. However, the performance increase of the container tower over the container block does not vary much (Table 4, column Imp (\%): 120\% increase in annual throughput). This shows that the storage size (\# storage locations) does not impact the percentage increase in annual throughput. Thus, terminal managers may implement the container tower instead of the container block for any block size while almost the same level of performance improvement can be achieved. In addition, due to better use of the height, the container tower can significantly increase the footprint utilization (see online Appendix C).

Observation 3. Table 5 shows that by increasing the number of lifts in the container tower, its performance improves (see the second column). This is expected, as with increasing the number of lifts, the average rotational distance of each lift decreases and the throughput increases consequently.

Observation 4. By increasing the number of lifts in a container tower, the improvement of its performance compared to the container block of the same storage capacity increases (see Table 5, Imp column). However, for a tower with only one lift, the container block outperforms the container tower of the same storage capacity (600 storage locations).

Observation 5. The fourth column of Table 5 shows how much increase in the performance of a container tower can be achieved by adding one additional lift to the tower. As it can be seen, a tower with two lifts can increase the throughput by $169 \%$ compared to the tower with one lift. However, this increase is less significant for the instance of five lifts versus four lifts. In fact, a second lift more than doubles the throughput capacity. This is due to the fact that not only the number of servers doubles, but also the service time per server reduces. 


\subsection{Comparing the cost of container tower and container block}

In this section we compare the investment cost of the container tower with the one of a container block using the results obtained in section 4.1. In such a comparison, different design parameters such as land usage, cost of land, and cost of technology influence the comparison. The cost of land and cost of technology might also vary from one terminal to another. Table 6 shows the results of a realistic range for footprint ratios $(\varphi)$, costs of land $\left(c_{l}\right)$, and costs of technology $\left(c_{t}\right)$. The results are obtained by using Equation (24). The detailed cost calculation for the optimal container tower and container block discussed in section 5.2 is given in online Appendix D. We vary each design parameter over five different alternative values while the other parameters are fixed. For each instance, we test for the given value of parameter, what the maximum value of technology cost ratio $(\gamma)$ should be such that the container tower still requires lower investment (technology cost ratio represents the average cost of technology per storage location for a container tower divided by the one for a container block, see Equation (20)).

Table 6: Sensitivity analysis for varying $\varphi, c_{l}, c_{t}$

\begin{tabular}{|c|c|c|c|c|c|}
\hline \multicolumn{2}{|c|}{$\begin{array}{l}\text { Sensitivity analysis 1: } \\
\text { maximum technology cost } \\
\text { ratio }(\gamma) \text { for different } \\
\text { footprint ratios }(\varphi)\end{array}$} & \multicolumn{2}{|c|}{$\begin{array}{l}\text { Sensitivity analysis } 2 \text { : } \\
\text { maximum technology cost ratio } \\
(\gamma) \text { for different costs of land }\left(c_{l}\right)\end{array}$} & \multicolumn{2}{|c|}{$\begin{array}{l}\text { Sensitivity analysis 3: maximum } \\
\text { technology cost ratio }(\gamma) \text { for } \\
\text { different costs of technology }\left(c_{t}\right)\end{array}$} \\
\hline $\begin{array}{l}\text { Footprint } \\
\text { ratio }(\varphi)\end{array}$ & $\begin{array}{l}\text { Technology } \\
\text { cost ratio }(\gamma)\end{array}$ & $\begin{array}{l}\text { Cost } \\
\text { land } \\
\left(€ / \mathbf{m}^{2}\right)\end{array}$ & $\begin{array}{l}\text { Technology cost } \\
\text { ratio }(\gamma)\end{array}$ & $\begin{array}{l}\text { Cost of } \\
\text { technology } \\
(€ / \text { location) }\end{array}$ & $\begin{array}{l}\text { Technology } \\
\text { cost ratio }(\gamma)\end{array}$ \\
\hline 1 & 1.00 & 100 & 1.10 & 500 & 1.67 \\
\hline $1.4^{*}$ & 1.18 & 150 & 1.15 & 1000 & 1.33 \\
\hline 1.5 & 1.20 & 177 & 1.18 & 1500 & 1.22 \\
\hline 2 & 1.31 & 200 & 1.20 & 1909 & 1.18 \\
\hline 3 & 1.41 & 250 & 1.25 & 2000 & 1.17 \\
\hline 4 & 1.46 & 300 & 1.30 & 2500 & 1.13 \\
\hline
\end{tabular}

${ }^{*}$ The bold numbers represent the results for the case discussed in section 5.2

Based on the results of sensitivity analysis, we make the following observations.

Observation 1. By increasing the footprint ratio $(\varphi)$, the technology cost ratio $(\gamma)$ also increases (see the second column of Table 6). However, the growth of technology cost ratio is less rapid (compare the increase of $\varphi$ from 1 to 4 with the increase of $\gamma$ from 1 to 1.46). For a container block where the land is not used 
efficiently (e.g. $\varphi=4$ ), if the container tower technology cost per location increases up to $46 \%$ (compared to the container block), the container tower still requires less investment in total.

Observation 2. By increasing the cost of land $\left(c_{l}\right)$, the technology cost ratio also increases (see the fourth column of Table 6). For the countries where land is cheaper, the container tower solution is more difficult to be financially justified. However, as the land becomes more expensive (e.g. in ports close to major cities), the technological investment per location for the container tower can increase while the tower remains cheaper in total. For instance, if the cost of a land reclamation project is as expensive as $300 € / \mathrm{m}^{2}$ (like in Maasvlakte 2 in Rotterdam), building container towers could be a viable alternative as long as the technology cost per location does not increase more than $30 \%$.

Observation 3. By increasing the cost of technology for a traditional container block $\left(c_{t}\right)$, the technology cost ratio decreases (see the sixth column of Table 6). For a container block where the cost of technology is $500 € /$ location, the technology cost ratio is 1.67 , while for a container block where the cost of technology is $2500 € /$ location, the technology cost ratio becomes 1.13 .

Our sensitivity analysis can help the terminal managers on deciding the appropriate type of terminal depending on the design parameters, footprint ratio, cost of land, and cost of technology.

\subsection{Optimal configuration to minimize the investment of a container tower for a given E(RT)}

In this section, we use the closed-form expressions obtained in section 4.2 in order to calculate the optimal radius and height of a container tower for a given expected retrieval time. In section 5.2, we obtained the optimal configuration (radius, height) of a container tower with a given volume which minimizes the expected retrieval time $\left(\rho^{*}=40, H^{*}=66, E\left(R T^{*}\right)=1.98\right)$. However, a terminal manager may wish to minimize the investment of container tower while a certain level of performance (expected retrieval time) is achieved. Table 7 shows the results for different levels of expected retrieval time. Among three different values of radius $\left(\rho_{1}, \rho_{2}, \rho_{3}\right)$, the one with the smallest positive value will be considered as the optimal radius length. The results in Table 7 shows that with increasing the given $E(R T)$, the optimal radius decreases and consequently the optimal height increases.

Table 7: Optimal radius and height of container tower for a given expected retrieval time $(E(R T))$ 


\begin{tabular}{llllll}
\hline $\begin{array}{l}\text { Given } \boldsymbol{E}(\boldsymbol{R} T) \\
(\text { min) }\end{array}$ & $\rho_{1}(\mathbf{m})$ & $\rho_{2}(\mathbf{m})$ & $\rho_{3}(\mathbf{m})$ & Optimal radius $\left(\rho^{*}(\mathbf{m})\right)$ & Optimal height $\left(H^{*}(\mathbf{m})\right)$ \\
\hline 2 & & & & \\
\hline 2.5 & -31.59 & 39.72 & 154.26 & 39.72 & 66.91 \\
3 & -28.08 & 32.34 & 213.14 & 32.34 & 100.94 \\
3.5 & -25.49 & 28.15 & 269.74 & 28.15 & 133.22 \\
\hline
\end{tabular}

\section{Conclusions and future research}

Capacity shortage in container terminals and in surface distribution networks are considered as the main constraints to future growth in sea shipping industry. To maximize container handling capacity, terminals need efficient equipment to load and unload container rapidly and they need to have higher storage capacity to store the containers. Unfortunately, the reality at many ports is that they have limited land to expand. Thus, they have to create land from the sea through expensive land reclamation projects. Instead of horizontal expansion through land reclamation, we propose an alternative vertical expansion solution: a "container warehouse". Leading world container ports have studied and developed several types of rectangular container warehouses which have been introduced in this paper. We propose a cylindrical container tower system which solves the land shortage problem, allows individual access to containers without the need for reshuffling and is sturdier against strong winds compared to rectangular systems.

To investigate the performance and financial feasibility of the container tower, we compare it with an existing container block of similar storage capacity. According to our analysis, container towers can increase the storage capacity in a given footprint. In addition, such a container tower can increase the annual throughput of a terminal by $120 \%$ compared to a container block. Our analysis shows that if the investment in material handling technology for a container tower per storage location is increased up to a certain level compared to the conventional container terminal, the container tower can still remain cheaper. The results of our numerical analysis can help terminal managers with selecting the appropriate system configuration to achieve the desired throughput and also to ensure the financial feasibility of the project.

The research on container warehouses is still at the beginning. It can be extended in various directions. Our computational model and analysis is based on a worst case scenario. For instance, we consider a random storage assignment policy as the control policy for the container towers. This means receiving containers are randomly assigned to storage locations. It might be worthwhile investigating the effect of other policies such as duration-of-stay (DOS) based policy on the performance of container towers. The previous results 
show that such a storage policy can reduce the response time specifically in practice up to $50 \%$ compared to a random storage policy (Yu and De Koster, 2009). In addition, we assume that terminal trucks and AGVs are always available to deliver and pick up containers. Researchers need to focus on synchronizing container tower operations and container handling operations in the other areas of future container terminals. 


\section{References}

Agerschou, H., Lundgren, H., Sorensen, T., Ernst, T., Korsgaard, J., Schmidt, L. R., Chi, W. K. (1983). Planning and Design of Ports and Marine Terminals. John Wiley and Sons, Chichester.

Autostadt, Car towers, retrieved on April 14, 2016, from: http://www.autostadt.de/en/explore-theautostadt/car-towers/.

Baird, A. J., Rother, D. (2013) Technical and economic evaluation of the floating container storage and transhipment terminal (FCSTT). Transportation Research Part C: Emerging Technologies, 30: 178-192.

Carlo, H.J., I.F.A. Vis, K.J. Roodbergen (2013) Seaside operations in container terminals: literature overview, trends, and research directions. Flexible Services and Manufacturing Journal: 1-39.

Carlo, H.J., I.F.A. Vis, K.J. Roodbergen (2014a) Storage yard operations in container terminals: Literature overview, trends, and research directions. European Journal of Operational Research 235(2): 412-430.

Carlo, H.J., I.F.A. Vis, K.J. Roodbergen (2014b) Transport operations in container terminals: Literature overview, trends, research directions and classification scheme. European Journal of Operational Research 236(1): 1-13.

Crainic, T. C., Dell'olmo, P., Ricciardi, N., Sgalambro, A. (2015) Modeling dry-port-based freight distribution planning. Transportation Research Part C: Emerging Technologies, 55: 518-534

Christiansen, M., Fagerholt, K., Nygreen, B., Ronen, D. (2013). Ship routing and scheduling in the new millennium. European Journal of Operational Research 228(3) 467-483.

De Koster MBM, Le-Duc T, Yu Y (2008) Optimal storage rack design for a 3-dimensional compact AS/RS. International Journal of Production Research. 46(6):1495-1514.

Dekker, R., Van der Heide, S., Van Asperen, E., Ypsilantis, P. (2012) A chassis exchange terminal to reduce truck congestion at container terminals. Flexible Services and Manufacturing Journal: 1-15.

Dooly, D. R., H. F. Lee. 2008. A shift-based sequencing method for twin-shuttle automated storage and retrieval systems. IIE Transactions 40(6) 586-594.

Dummit, D. S. and Foote, R. M. Abstract Algebra, 1st ed. Englewood Cliffs, NJ: Prentice-Hall, pp. 547 and $551,1998$.

ECT (2012). Euromax: a new standard in container handling. Rotterdam, the Netherlands.

Eilo and Global Inc., Advantages/features of round space structure, retrieved on April 14, 2016, from: http://www.autostadt.de/en/explore-the-autostadt/car-towers/.

Ez-Indus. (2017) Ultra high container warehouse system, retrieved April 04, 2017, from http://www.ezindus.com/emain.php?page=emenu2\&sub=eez m2.

European Gateway Services (2012). Key figures - edition 2012. Retrieved on May 24, 2017 from http://www.ect.nl/en/content/publications-0.

Fransoo, J. C., C. Y. Lee. (2013). The critical role of ocean container transport in global supply chain performance. Production and Operations Management 22(2) 253-268.

Goetschalckx M, Ratliff HD (1990) Shared storage policies based on the duration stay of unit loads. Management Sci. 36(9): 1120-1132. 
Germangray's scale modelling (2017). Automated container transport system (AUTOCON). Retrieved on May 22, 2017 from http://www.iemsjl.org/journal/article.php?code=1556.

Gharehgozli, A. H., Vernooij, F. G., Zaerpour, N. (2017a) A Simulation Study of the Performance of Twin Automated Stacking Cranes at a Seaport Container Terminal. European Journal of Operational Research. 261(1): 108-128.

Gharehgozli, A. H., J. Mileski, O. Duru (2017b). Heuristic Estimation of Container Stacking and Reshuffling Operations under the Containership Delay Factor and Mega-Ship Challenge. Maritime Policy and Management. 44(3): 373-391.

Gharehgozli, A.H., De Koster, R., Jansen, R (2017c) Collaborative solutions for inter terminal transport. International Journal of Production Research. Forthcoming.

Gharehgozli, A. H., Y. Yu, X. Zhang, R. de Koster. (2017d). Polynomial Time algorithms to Minimize Total Travel Time in a Two-Depot AS/RS. Transportation Science. 55(1): 19-33.

Gharehgozli, A. H., Roy, D. \& de Koster, R., (2016). Sea container terminals: New technologies and OR models. Maritime Economics \& Logistics. 18(2): 103-140.

Gharehgozli, A. H., G. Laporte, Y. Yu, de Koster, R. (2015). Scheduling twin yard cranes in a container block. Transportation Science 49(3) 686-705.

Gharehgozli, A. H., Y. Yu, R. De Koster, J. T. Udding (2014a). A decision-tree stacking heuristic minimizing the expected number of reshuffles at a container terminal. International Journal of Production Research 52(9) 2592-2611.

Gharehgozli, A. H., Y. Yu, Y., de Koster, R. \& Udding, J. T. (2014b). An Exact Method for Scheduling a Yard Crane. European Journal of Operational Research, 235(2), 431-447.

Gorman M., J. P. Clarke, A. H. Gharehgozli, M. Hewitt, R. de Koster, D. Roy. (2014). State of the Practice: Application of OR/MS in Freight Transportation. Interfaces 44(6), 535-554.

Gottwald ASC Automated Stacking Cranes (2016), retrieved 24 May 2016 from, $\underline{\text { https://www.terex.com/port- }}$ solutions/en/cs/groups/webcontent/@web/@tps/documents/web_content/ucm03_072352.pdf.

GRID Logistics Inc. (2017). What Is the SuperDock? Retreived on May 22, 2017 from http://s474091609.onlinehome.us/gridweb/superdock/.

Gue, K. R. (2006). Very high density storage systems. IIE Transactions 38(1) 79-90.

Gue, K.R., Kim B.S. (2007) Puzzle-based storage systems. Naval Research Logistics. 54(5):556-567.

Gue, H.R. (2014) A New Angle on Container Ports. Retrieved 24 April 2017 from, https://kevingue.wordpress.com/2014/09/09/new-angle-on-container-ports/

Gue, K. R., Ivanovi c, G., Russell D. M. (2012) A unit-load warehouse with multiple pickup and deposit points and non-traditional aisles. Transportation Research Part E: Logistics and Transportation Review 48(4): 795-806.

Gue, K. R., Meller, R. D. (2009) Aisle configurations for unit-load warehouses. IIE Transactions 41(3): 171-182. 
Günther, H. O., Kim, K. H. (2005) Container Terminals and Automated Transport Systems Logistics Control Issues and Quantitative Decision Support. Springer, Berlin/Heidelberg.

Han, M. H., L. F. McGinnis, J. S. Shieh, J. A. White. (1987). On sequencing retrievals in an automated storage/retrieval system. IIE Transactions 19(1) 56-66.

Hausman, W.H., L.B. Schwarz, S.C. Graves. 1976. Optimal storage assignment in automatic warehousing systems. Management Science 22(6) 629-638.

Holland Container Innovation (2016). The 4Benefits of the 4 fold container, retrieved on June 22, 2016 from http://hcinnovations.nl/wp-content/uploads/2016/06/4FOLD_containers_English.pdf

Hu, Y. H., S. Y. Huang, C. Chen, W. J. Hsu, A. C. Toh, C. K. Loh, T. Song. 2005. Travel time analysis of a new automated storage and retrieval system. Computers \& Operations Research 32(6) 1515-1544.

Hu, H., Lee, B. K., Huang, Y., Lee, L. H., Chew, E. P. (2013) Performance analysis on transfer platforms in frame bridge based automated container terminals. Mathematical Problems in Engineering, 2013, 18.

Iannone, F. (2012) The private and social cost efficiency of port hinterland container distribution through a regional logistics system. Transportation Research Part A: Policy and Practice 46(9): 1424-1448.

Ivanović (2014). Better Container Yards, retrieved on June 22, 2016 from https://containerterminals.wordpress.com/

Kho, F. (2013). Kalmar's proposal received a commendation award in the Next Generation Container Port Challenge. Retrieved on April 14, 2016, from: http://port2060.kalmarglobal.com/designing-the-nextgeneration-container-port/.

Kemme, N. (2012) Effects of storage block layout and automated yard crane systems on the performance of seaport container terminals. OR Spectrum 34: 563-591.

Kim, K. H. (1997). Evaluation of the Number of Rehandles in Container Yards. Computers \& Industrial Engineering 32 (4): 701-711.

Kim, K., Park, Y. M., Jin, M. J. (2008) An optimal layout of container yards. OR Spectrum 30: 675-695.

Kim, K. H., Thi Phan, M. H., Woo, Y. J. (2012). New conceptual handling systems in container terminals. Industrial Engineering \& Management systems, 11(3): 299-309.

Kosmatopoulos, E. B., Liu, Q., Ioannou, P. (2002) Design and Optimization of a Conceptual Automated Yard Using Overhead Grid Rail System. METRANS Transportation Center, Los Angeles, California.

Lee, B. K., and K. H. Kim. (2010). Optimizing the Block Size in Container Yards. Transportation Research Part E: Logistics and Transportation Review 46 (1): 120-135.

Lee, B. K., Kim, K. H. (2013) Optimizing the yard layout in container terminals. OR Spectrum 35: 363398.

Lee MK, Elsayed EA (2005) Optimization of warehouse storage capacity under a dedicated storage policy. International Journal of Production Research. 43(9):1785-1805.

Lee, C. Y., Song, D. P. (2017) Ocean container transport in global supply chains: Overview and research opportunities. Transportation Research Part B: Methodological 95 442-474. 
Lin, D. Y., Lee, Y. J., Lee, Y. (2015) The container retrieval problem with respect to relocation. Transportation Research Part C: Emerging Technologies, 52:132-143

Liu, M., Lee, C. Y., Zhang, Z., Chu, C. (2016) Bi-objective optimization for the container terminal integrated planning, Transportation Research Part B: Methodological, 93 720-749.

Marine Insight (2013). The Yangshan Deep Water Port - The Biggest Deep Water Port in the World, retrieved on June 22, 2016 from http://www.marineinsight.com/ports/the-yangshan-deep-water-port-thebiggest-deep-water-port-in-the-world/

Matinlauri, I. (2015) Back to the future, retrieved on June 22, 2016 from http://port2060.kalmarglobal.com/back-to-the-future/

Maersk. (2015). The World's Largest Ship, Retrieved on March 24, 2016, from http://www.maersk.com/en/hardware/triple-e.Ruben.

Meng, Q., Wang, S., Andersson, H., Thun, K. (2014) Containership routing and scheduling in liner shipping: Overview and future research directions. Transportation Science 48(2) 265-280.

Murty, K. G., Liu, J., Wan, Y. W., Linn, R. (2005) A decision support system for operations in a container terminal. Decision Support Systems 39(3): 309-332.

Öztürkoǵlu , Ö, Gue, K. R., Meller, R. D. (2012) Optimal unit-load warehouse designs for single command operations. IIE Transactions 44(6): 459-475.

Petering, M. E. H. (2011) Decision support for yard capacity, fleet composition, truck substitutability, and scalability issues at seaport container terminals. Transportation Research Part E: Logistics and Transportation Review 47(1): 85-103.

Petering, M. E. H., Murty, K. G. (2009) Effect of block length and yard crane deployment systems on overall performance at a seaport container transshipment terminal. Computers \& Operations Research 36(5):1711-1725.

Roy, D., Gupta, A., Parhi, S., de Koster, M.B.M. (2014) Optimal Stack Layout in a Sea Container Terminal with Automated Lifting Vehicles. ERIM Report Series Reference No. ERS-2014-012-LIS. Available at SSRN: http://ssrn.com/abstract=2491023.

Sari Z, Saygin C, Ghouali N (2005) Travel-time models for flow-rack automated storage and retrieval systems. International Journal of Advanced Manufacturing Technology 25(9-10):979-987.

SingaPort (2013) Next Generation Container Port, Reterieved on May 19, 2017 from https://www.isem.nus.edu.sg/research/C4NGL/achievement/.

Stadtler H (1996) An operational planning concept for deep lane storage systems. Production and Operations Management 5(3):266-282.

Stahlbock, R., Voß, S. (2008) Operations research at container terminals: a literature update. OR Spectrum 30(1): 1-52.

Steenken, D., Voß, S., Stahlbock, R. (2004) Container terminal operation and operations research a classification and literature review. OR Spectrum (26): 3-49.

Sun, L., Yin, Y. (2017) Discovering themes and trends in transportation research using topic modeling. Transportation Research Part C: Emerging Technologies, 77: 49-66. 
Van den Berg, J. P., A. J. R. M. Gademann. (1999). Optimal routing in an automated storage/retrieval system with dedicated storage. IIE Transactions 31(5) 407.

Veenstra, A., Zuidwijk, R., Van Asperen, E. (2012) The extended gate concept for container terminals: Expanding the notion of dry ports. Maritime Economics \& Logistics 14: 1479-2931.

Vis, I.F.A., de Koster, R. (2003) Transshipment of containers at a container terminal: An overview. European Journal of Operational Research 147(1): 1-16.

Vis, I.F.A. (2006), Survey of Research in the Design and Control of Automated Guided Vehicle Systems, European Journal of Operational Research 170(3), 677-709.

VMW Systems. (2017). Container Handling Systems, retrieved on April 21, 2017 from: https://www.youtube.com/watch?v=72HokOJ 5qw

Wampler, S. (2010) Plan floated to ship cargo inspection offshore, retrieved on July 8, 2016 from https://www.llnl.gov/news/plan-floated-ship-cargo-inspection-offshore

Wiese J, Kliewer N, Suhl L (2009) A survey of container terminal characteristics and equipment types. Technical Report 0901, DS\&OR Lab, University of Paderborn. Retrieved on June 24, 2016 from https://wiwi.uni-

paderborn.de/fileadmin/dep31s5/Publikationen/A_Survey_of_Container_Terminal_Characteristics_and Equipment Types.pdf

Wiese, J., Suhl, L., Kliewer, N. (2011) An analytical model for designing yard layouts of a straddle carrier based container terminal. Flexible Services and Manufacturing Journal: 1-37.

Wu, G., Xu, X., Gong, Y., de Koster, R., Zou, B. (2017). Optimal Planning and Design for Compact Automated Parking Systems. Working paper.

Yu, Y., R. de Koster. (2009a). Designing an optimal turnover-based storage rack for a 3D compact automated storage and retrieval system. International Journal of Production Research 47(6) 1551-1571.

Yu, Y., R. de Koster. (2009b). Optimal zone boundaries for two-class-based compact three-dimensional automated storage and retrieval systems. IIE Transactions 41 (3) 194-208.

Yu Y, R. de Koster (2012) Sequencing heuristics for storing and retrieving unit loads in 3D compact automated warehousing systems. IIE Transactions. 44(2):69-87.

Zaerpour, N., Y. Yu, R. de Koster (2017) "Small is Beautiful: A Framework for Evaluating and Optimizing Live-cube Compact Storage Systems". Transportation Science, http://dx.doi.org/10.1287/trsc.2015.0586.

Zaerpour, N., Y. Yu, R. de Koster (2015). "Storing Fresh Produce for Fast Retrieval in an Automated Compact Cross-dock System". Production and Operations Management 24 (8) 1266-1284.

Zhen, L., Lee, L. H., Chew, E. P., Chang, D. F., Xu, Z. X. 2012. A Comparative Study on Two Types of Automated Container Terminal Systems. IEEE Transactions on Automation Science and Engineering, 9(1): 56-69.

Zhou C, Chew EP, Lee LH, Liu D (2016) An introduction and performance evaluation of the GRID system for transshipment terminals. Simulation 92(3):277-293.

Zhou, C., Chew, E. P., Lee, L. H. (2017) Information-Based Allocation Strategy for GRID-Based Transshipment Automated Container Terminal. Transportation Science. Forthcoming. 
Zhen, L., Xu, Z., Wang, K., Ding, Y. (2016) Multi-period yard template planning in container terminals, Transportation Research Part B: Methodological 93: 700-719.

Zhu, M., Fan, X, Cheng, H., He, Q. (2010) Modeling and simulation of automated container terminal operation. Journal of Computers 5(6): 951-957.

Zuidwijk, R.A., Veenstra, A.W. \& Asperen, E. van (2012). The extended gate concept for container terminals: Expanding the notion of dry ports. Maritime Economics and Logistics, 14 (1), 14-32.

Zuidwijk, R.A. \& Veenstra, A.W. (2015). The Value of Information in Container Transport. Transportation Science, 49 (3), 675-685. 